Кухар B. B.

Нагнібеда М. М.

\title{
ТЕОРЕТИЧНЕ ДОСЛІДЖЕННЯ НАПРУЖЕНОГО СТАНУ ТА РОЗРАХУНОК ЗАЛИШКОВИХ НАПРУЖЕНЬ ПРИ ГНУТТІ ПРОФІЛІВ ВІДКРИТОГО ПЕРЕРІЗУ
}

На сьогодні гнутий профіль $є$ одним з найбільш поширених продуктів обробки металів тиском на ринку України і світу, займаючи важливу нішу в промисловому виробництві. Найширше і найрізноманітніше застосування подібні спеціальні профілі знаходять в сучасному будівництві, автомобілебудуванні та літакобудуванні [1-3].

Гнутий профіль отримують в ході процесу пластичної деформації заготовки, у тому числі в штампі. Знаходячись в області пластичної деформації, форма заготовки може бути змінена, а величина напружень, яким піддається заготовка, вища за границю текучості, але нижча за границю міцності матеріалу на розрив $[3,4]$. Було розглянуто вплив ефекту зміцнення на величину пружинення металу, що деформують у V-подібних штампах $[2,5]$. Також відомо, що листова заготовка схильна до певного пружинення при гнутті на багато-перехідних станах [5].

Технології гнуття-прокатки профілів дуже різноманітні: згинання може бути виконано на профілезгинальних станах різної конструкції, кількість переходів гнуття-формовки залежить від складності профілю та властивостей матеріалу заготовки і тому подібне. Ці обставини впливають на динаміку зміни напружено-деформованого стану заготовки при багатоперехідному гнутті і, відповідно, на залишкові напруження в профілі, що мають вплив і на його фінішну геометричну форму [6, 7]. Це робить актуальним вдосконалення теоретичних методик визначення кута пружинення в заготовках [8]. Дані теоретичного аналізу, отримані методом скінчених елементів, дозволяють визначити значення залишкового напруження та деформації, наближені до дійсних, проте погрішність розрахунків є непрогнозованою і залежить від початкових даних, що задаються, і граничних умов [9-12].

Внутрішні напруження металу призводять до часткового відновлення початкової форми заготовки. Кут пружинення може бути визначений на основі теоретичного аналізу результатів чисельного моделювання, а метод скінчених елементів є основним при вивченні параметрів процесу гнуття і дає уявлення про аналітичну модель гнуття листового металу і залишкового напруження у середині заготовки, що характеризує розвиток кута пружинення $[13,14]$. При цьому метод скінчених елементів не дозволяє отримати розрахункові залежності, які можуть бути рекомендовані технологам.

Таким чином, аналіз останніх досліджень і публікацій показує необхідність в дослідженні залишкових напружень при згинальних операціях (у тому числі, при багатоперехідному гнутті) і отриманні аналітичних розрахунків залежностей для визначення показників напруженого стану, які будуть використані в технологічних розрахунках $[15,16]$.

Метою дослідження є розробка математичної моделі напружено-деформованого стану листової заготовки при згинальних операціях і розрахунок залишкових напружень у матеріалі при гнутті профілів з відкритим поперечним перерізом.

Схема деформації профілю при пружиненні наведена на рис. 1.

Розглянемо напружено-деформований стан металу при згинанні профілю, застосувавши метод механіки суцільних середовищ з використанням полів швидкостей переміщень $[17,18]$. 


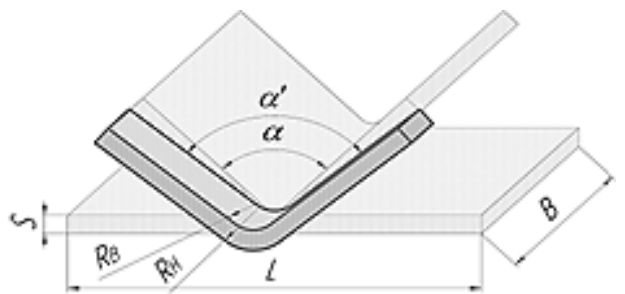

Рис. 1. Схема пружинення профілю після гнуття:

$\mathrm{S}$ - товщина; $\mathrm{B}$ - ширина; $\mathrm{L}$ - довжина; $\mathrm{R}_{\mathrm{B}}$ - радіус внутрішній; $\mathrm{R}_{\mathrm{H}}$ - радіус зовнішній; $\alpha$ - кут заготовки, що задано; $\alpha$ ' - кут заготовки при пружиненні

Відомо, що компоненти тензора швидкості деформацій: $\dot{\varepsilon}_{r}, \dot{\varepsilon}_{\varphi}, \dot{\varepsilon}_{z}, \dot{\gamma}_{r \varphi}, \dot{\gamma}_{\varphi z}, \dot{\gamma}_{z r}$ пов'язані зі швидкостями переміщень $V_{r}, V_{\varphi}, V_{z}$ наступними рівняннями:

$$
\left.\begin{array}{l}
\dot{\varepsilon}_{r}=\frac{\partial V_{r}}{\partial r} ; \dot{\varepsilon}_{\varphi}=\frac{1 \partial V_{\varphi}}{r \partial \varphi}+\frac{V_{r}}{r} ; \dot{\varepsilon}_{z}=\frac{\partial V_{z}}{\partial z} ; \\
\dot{\gamma}_{r \varphi}=\frac{\partial V_{\varphi}}{\partial r}-\frac{V_{\varphi}}{r}+\frac{1 \partial V_{r}}{r \partial \varphi} ; \dot{\gamma}_{\varphi z}=\frac{\partial V_{\varphi}}{\partial z}+\frac{1 \partial V_{r}}{r \partial \varphi} ; \dot{\gamma}_{z r}=\frac{\partial V_{r}}{\partial z}+\frac{\partial V_{z}}{\partial r}
\end{array}\right\}
$$

Запишемо зв'язок між компонентами тензору швидкостей деформацій і компонентами тензору напружень $\left(\sigma_{r} ; \sigma_{\varphi} ; \sigma_{z} ; \tau_{r \varphi} ; \tau_{\varphi z} ; \tau_{z r}\right)$ :

$$
\left.\begin{array}{l}
\sigma_{r}=\sigma+2 \mu_{i} \dot{\varepsilon}_{r} ; \sigma_{\varphi}=\sigma+2 \mu_{i} \dot{\varepsilon}_{\varphi} ; \sigma_{z}=\sigma+2 \mu_{i} \dot{\varepsilon}_{z} ; \\
\tau_{r \varphi}=\mu_{i} \dot{\gamma}_{r \varphi} ; \tau_{\varphi z}=\mu_{i} \dot{\gamma}_{\varphi z} ; \tau_{z r}=\mu_{i} \dot{\gamma}_{z r} .
\end{array}\right\}
$$

Тут $\mu_{i}$ - коефіцієнт жорсткості, залежний від характеристик механічних властивостей металу, а також від отримуваних тілом деформацій і їх швидкостей:

$$
\mu_{i}=\frac{\sigma_{i}}{3 \dot{\varepsilon}_{i}}
$$

де $\sigma_{i}$ та $\dot{\varepsilon}_{i}$-інтенсивності напружень і швидкостей деформацій відповідно.

Інтенсивність напружень $\sigma_{i}$ і швидкостей деформацій $\dot{\varepsilon}_{i}$ визначаються виразами:

$$
\begin{aligned}
& \sigma_{i}=\frac{1}{\sqrt{2}}\left[\left(\sigma_{r}-\sigma_{\varphi}\right)^{2}+\left(\sigma_{\varphi}-\sigma_{z}\right)^{2}+\left(\sigma_{z}-\sigma_{r}\right)^{2}+6\left(\tau_{r \varphi}^{2}+\tau_{\varphi z}^{2}+\tau_{z r}^{2}\right)\right]^{1 / 2} \\
& \dot{\varepsilon}_{i}=\frac{\sqrt{2}}{3}\left[\left(\dot{\varepsilon}_{r}-\dot{\varepsilon}_{\varphi}\right)^{2}+\left(\dot{\varepsilon}_{\varphi}-\dot{\varepsilon}_{z}\right)^{2}+\left(\dot{\varepsilon}_{z}-\dot{\varepsilon}_{r}\right)^{2}+\frac{3}{2}\left(\dot{\gamma}_{r \varphi}^{2}+\dot{\gamma}_{\varphi z}^{2}+\dot{\gamma}_{z r}^{2}\right)\right]^{1 / 2} .
\end{aligned}
$$

Для ідеально пластичного матеріалу приймають $\sigma_{i}=\sigma_{s}$. Для матеріалу, що зміцнюється, інтенсивність напружень представляють у вигляді функції, яка описує криву текучості матеріалу: $\sigma_{i}=f\left(\varepsilon_{i}\right)$, де $\varepsilon_{i}$ - інтенсивність деформацій. Такі функції можуть бути отримані у вигляді ступеневої функції: $\sigma_{i}=A \varepsilon_{i}^{m}$, де $A, m$ - сталі для досліджуваного матеріалу, які визначаються експериментально після стандартних випробувань зразків на розтягування-стискання. 
Інтенсивність деформацій $\varepsilon_{i}$ знаходять згідно з рівнянням:

$$
\varepsilon_{i}=\frac{\sqrt{2}}{3}\left[\left(e_{r}-e_{\varphi}\right)^{2}+\left(e_{\varphi}-e_{z}\right)^{2}+\left(e_{z}-e_{r}\right)^{2}+\frac{3}{2}\left(\gamma_{r \varphi}^{2}+\gamma_{\varphi z}^{2}+\gamma_{z r}^{2}\right)\right]^{1 / 2} .
$$

Залежності для пружної формозміни відрізняються від аналогічних залежностей для процесу пластичної формозміни лише значенням коефіцієнта жорсткості $\mu_{i}$, який при пластичній формозміні визначається виразом (3), а при пружному - виразом:

$$
\mu_{i}=\frac{E}{2}(1+v),
$$

де $E$ - модуль пружності першого роду; $v$ - коефіцієнт Пуассону.

Таким чином, можна скористатися рівняннями методу механіки суцільних середовищ [17-19] з використанням поля швидкостей переміщень (приймаючи $v=0,5$ ). При пружиненні переміщення матеріальних точок в місці вигину протилежні до переміщень при пластичній формозміні.

Знайдемо напруження при пружній формозміні місця вигину. Вводимо значення коефіцієнту жорсткості (6) і швидкостей деформацій в рівняння рівноваги [18-20]:

$$
\frac{\partial \sigma}{\partial r}=\frac{E V_{0}}{2(1+v)\left(R_{H}+R_{B}\right)}\left(3 \frac{1}{r}+\frac{R_{H} R_{B}}{r^{3}}\right) ; \frac{\partial \sigma}{r \partial \varphi}=0 ; \frac{\partial \sigma}{\partial \varphi}=0,
$$

де $R_{H}$ та $R_{B}$ - зовнішній та внутрішній радіуси згинання заготовки; $r$ - поточний радіус у поперечному перерізі заготовки, що згинають; $V_{0}$ - швидкість руху інструменту.

Інтегруючи систему диференціальних рівнянь у частинних похідних (7), отримуємо:

$$
\sigma_{i}=\frac{E V_{0}}{2(1+v)\left(R_{H}+R_{B}\right)}\left(3 \ln r+\frac{R_{H} R_{B}}{r^{2}}\right)+C .
$$

Внесемо значення (6), (8) у вираз (2) і запишемо:

$$
\left.\begin{array}{c}
\sigma_{r}=\frac{E V_{0}}{2(1+v)\left(R_{H}+R_{B}\right)}\left(3 \ln r-2 \frac{R_{H} R_{B}}{r^{2}}\right)+C ; \sigma_{\varphi}=\frac{E V_{0}}{2(1+v)\left(R_{H}+R_{B}\right)}\left(3 \ln r-\frac{5}{2} \frac{R_{H} R_{B}}{r^{2}}+2\right)+C ; \\
\sigma_{z}=\frac{E V_{0}}{2(1+v)\left(R_{H}+R_{B}\right)}\left(3 \ln r-\frac{R_{H} R_{B}}{2 r^{2}}\right)+C .
\end{array}\right\}
$$

Підставляючи (9) у вираз (4), маємо наступне значення інтенсивності напружень:

$$
\sigma_{i}=\sqrt{3} \frac{E V_{0}}{(1+v)\left(R_{H}+R_{B}\right)}\left[1-\frac{R_{H} R_{B}}{r^{2}}\right] .
$$

Значення довільної постійної інтегрування визначимо з граничних умов $\sigma_{\varphi}=0$ при $r=\rho$, де $\rho$ - радіус нейтрального шару напруження.

3 рівнянь (9) та (10) знаходили: 


$$
\begin{gathered}
\rho=\sqrt{R_{H} R_{B}} ; \\
C=-\frac{E V_{0}}{2(1+v)\left(R_{H}+R_{B}\right)}\left(3 \ln \rho-\frac{5}{2} \frac{R_{H} R_{B}}{r^{2}}+2\right) .
\end{gathered}
$$

Тоді

$$
\left.\begin{array}{l}
\sigma_{r}=-\frac{E V_{0}}{2(1+v)\left(R_{H}+R_{B}\right)}\left[3 \ln \frac{r}{\rho}-4+\frac{3}{2} R_{H} R_{B}\left(\frac{1}{r^{2}}+\frac{5}{3 \rho^{2}}\right) ;\right. \\
\sigma_{\varphi}=-\frac{E V_{0}}{2(1+v)\left(R_{H}+R_{B}\right)}\left[3 \ln \frac{r}{\rho}-\frac{5}{2} R_{H} R_{B}\left(\frac{1}{r^{2}}+\frac{1}{\rho^{2}}\right)\right] ; \\
\sigma_{z}=-\frac{E V_{0}}{2(1+v)\left(R_{H}+R_{B}\right)}\left[3 \ln \frac{r}{\rho}-2+\frac{1}{2} R_{H} R_{B}\left(5 \frac{1}{\rho^{2}}-\frac{1}{r^{2}}\right)\right] .
\end{array}\right\}
$$

Напруження $\sigma_{\varphi}$ на скінчених перерізах урівноважуються моментом $M$, що вигинає:

$$
\begin{aligned}
& \int_{R_{B}}^{R_{H}} \sigma_{\varphi} r d r=-M ; \\
& \int_{R_{B}}^{R_{H}} \sigma_{\varphi} d r=0 .
\end{aligned}
$$

Підставивши $V_{0}$ у вираз швидкостей деформацій, інтенсивності швидкостей деформацій та інтенсивності напружень, запишемо:

$$
\left.\begin{array}{c}
\dot{\varepsilon}_{r}=\frac{2(1+v) M}{E K}\left(1-\frac{R_{H} R_{B}}{r^{2}}\right) ; \dot{\varepsilon}_{\varphi}=\frac{2(1+v) M}{E K}\left(1-\frac{R_{H} R_{B}}{r^{2}}\right) ; \\
\dot{\gamma}_{r \varphi}=0 ; \dot{\gamma}_{\varphi z}=0 ; \dot{\gamma}_{r z}=0 ; \dot{\varepsilon}_{z}=0 . \\
e_{i}=\frac{2}{\sqrt{3}} \frac{2(1+v) M}{E K}\left|1-\frac{R_{H} R_{B}}{r^{2}}\right| ; \\
\sigma_{r}=2 \sqrt{2} \frac{M}{K}\left|1-\frac{R_{H} R_{B}}{r^{2}}\right| ; \\
M\left[3 \ln \frac{r}{\rho}-4+\frac{3}{2} R_{H} R_{B}\left(\frac{1}{r^{2}}+\frac{5}{3 \rho^{2}}\right)\right] ; \sigma_{\varphi}=-\frac{M}{K}\left[3 \ln \frac{r}{\rho}+\frac{5}{2} R_{H} R_{B}\left(\frac{1}{r^{2}}-\frac{1}{\rho^{2}}\right)\right] ; \\
\sigma_{z}=-\frac{M}{K}\left[3 \ln \frac{r}{\rho}-2+\frac{1}{2} R_{H} R_{B}\left(5 \frac{1}{\rho^{2}}-\frac{1}{r^{2}}\right)\right] .
\end{array}\right\}
$$


У формулах (16-19) значення $K$ розраховують як [17, 18]:

$$
K=-3\left(\frac{R_{H}^{3}-R_{B}^{3}}{2}\right)\left(\ln \frac{R_{H}}{R_{B}}-\frac{1}{2}\right)+\frac{5}{2} R_{H} R_{B} \rho\left[\ln \frac{R_{H}}{R_{B}}-\frac{1}{\rho^{2}}\left(\frac{R_{H}^{2}-R_{B}^{2}}{2}\right)\right]
$$

Після нескладних перетворень отримаємо рівняння для визначення радіусу $\rho$ нейтрального шару напружень:

$$
3\left(R_{H}-R_{B}\right)\left(\ln \frac{R_{H}}{R_{B}}\right)+\frac{5}{2} R_{H} R_{B}\left(\frac{1}{R_{H}-R_{B}}-\frac{R_{H}-R_{B}}{\rho^{2}}\right)=0 .
$$

Пружна енергія деформації $Y$ визначається по формулі, що і кількість енергії дисипацiї [16-18]:

$$
Y=\mu_{i}\left(2 \dot{\varepsilon}_{r}^{2}+2 \dot{\varepsilon}_{\varphi}^{2}+2 \dot{\varepsilon}_{z}^{2}+\dot{\gamma}_{r \varphi}^{2}+\dot{\gamma}_{\varphi z}^{2}+\dot{\gamma}_{z r}^{2}\right)
$$

Підставивши значення з виразів (6), (16) у вираз (22), запишемо:

$$
Y=\frac{8(1-v) M^{2}}{E K^{2}}\left(1-\frac{R_{H} R_{B}}{r^{2}}\right)^{2}
$$

Момент, що вигинає, визначиться з наступної формули:

$$
M=\int_{R_{B}}^{R_{H}} \sigma_{\varphi}-\sqrt{R_{H} R_{B}} d r
$$

Розбиваючи цей інтеграл на два інтеграли і враховуючи при цьому вирази (21) i (22) для тангенціального нормального напруження при пластичній формозміні, після перетворень отримуємо:

$$
M=\frac{\sigma_{S}}{2 \sqrt{3}} b\left(R_{H}-R_{B}\right)^{2} .
$$

де $b$ - плече згинання.

Знаючи зовнішній $R_{H}$ і внутрішній $R_{B}$ радіуси місця вигину, по формулах (21) і (22) визначаємо компоненти тензора напружень при пластичній деформації, а по формулі (24) момент $M$, що згинає. Підставляючи значення $M$, а також зовнішній і внутрішній радіуси місця вигину у формули (19), знаходимо компоненти тензору напружень при пружній деформації місця вигину. Віднімаючи компоненти другого тензора напружень 3 компонента першого, визначаємо залишкові напруження у металі в місці згинання.

Розглянемо напружено-деформований стан металу при згинанні за схемою і за профілем. Застосуємо метод механіки суцільних середовищ [18] з використанням поля швидкостей переміщень і методику розрахунку, викладену в роботі [17].

При розрахунку ступеня зміцнення листової заготовки в процесі профілювання важливо коректно визначити ступінь деформації. 
Відомо [20], що при профілюванні методом валкового формування деформація здійснюється в результаті чистого вигину заготовки і розтягування шарів металу на ії зовнішній поверхні:

$$
\varepsilon_{i}=\frac{2}{\sqrt{3}} \ln \left\{\left[1+\frac{\mathrm{S}_{0}(1-k)}{R_{B}+S_{0} k}\right] \frac{S_{0}}{S}\right\},
$$

де $k$ - коефіцієнт зміщення нейтрального шару заготовки, що згинають:

$$
k=\frac{\sqrt{\left(R_{B}+S_{0}\right) R_{B}}-R_{B}}{S_{0}},
$$

де $S_{0}$ - вихідна товщина заготовки;

$S$ - товщина гнутого профілю з урахуванням стоншення в процесі профілювання.

Величина стоншення $\left(\Delta S=S_{0}-S\right)$ :

$$
\Delta S=0,0081 S_{0} \sqrt{\frac{b}{R_{B} / S_{0}}} .
$$

Величину опору матеріалу деформації при профілюванні визначали згідно з гіпотезою єдиної кривої з випробувань зразків на розтяг (зразки вирізали згідно вимогам стандарту в поперечному напрямку відносно напряму профілізації).

Рівняння, що описують модель зміцнення матеріалів записували згідно з даними джерела [20]:

$$
\begin{gathered}
\text { сталь 10ХНДП: } \sigma_{i}=-3869,2 \varepsilon_{i}^{2}+1777,0 \varepsilon_{i}+233,14 ; \\
\text { сталь 3Гпс: } \sigma_{i}=-5527,6 \varepsilon_{i}^{2}+2273,3 \varepsilon_{i}+26274 ; \\
\text { сталь 09Г2: } \sigma_{i}=-762,53 \varepsilon_{i}^{2}+673,06 \varepsilon_{i}+410,86 ; \\
\text { сталь 10Г2ФБЮ: } \sigma_{i}=-34683 \varepsilon_{i}^{3}-16972 \varepsilon_{i}^{2}+2755,4 \varepsilon_{i}+515,87 .
\end{gathered}
$$

Також, для врахування властивостей реального матеріалу, нами були апроксимовані дані власних експериментальних досліджень [21]:

$$
\text { сталь 08кп: } \sigma_{i}=48,038 \ln \left(\varepsilon_{i}\right)+601,085 \text {. }
$$

Достовірність апроксимації для рівнянь (27)-(31) була на рівні $R^{2} \geq 0,94$.

Якщо стандартний і оцінюваний профілі мають однакове число місць вигину, то достатньо за отриманими залежностями визначити опір матеріалу профілю деформації з урахуванням товщини заготовки, радіусу вигину, плеча вигину, ширини полиць, що згинають, $\mathrm{i}$ ступеня деформації.

Компоненти напружень для зовнішнього шару (пластична деформація), $R_{H}=r \geq \rho$ :

$$
\left.\begin{array}{c}
\sigma_{r}=\frac{\sqrt{3}}{2} \sigma_{S} \ln \frac{R_{H}}{r}=0,867 \sigma_{S} \ln \frac{R_{H}}{r} ; \quad \sigma_{\varphi}=\frac{\sigma_{S}}{\sqrt{3}}\left(\frac{3}{2} \ln \frac{R_{H}}{r}-2\right)=0,578 \sigma_{S}\left(\frac{3}{2} \ln \frac{R_{H}}{r}-2\right) ; \\
\sigma_{z}=\frac{\sigma_{S}}{\sqrt{3}}\left(\frac{3}{2} \ln \frac{R_{H}}{r}-1\right)=0,578 \sigma_{S}\left(\frac{3}{2} \ln \frac{R_{H}}{r}-1\right) .
\end{array}\right\}
$$


Компоненти напружень для внутрішнього шару (пластична деформація), $R_{H}=r \leq \rho$ :

$$
\left.\begin{array}{rl}
\sigma_{r}=\frac{\sqrt{3}}{2} \sigma_{S} \ln \frac{R_{B}}{r} & =0,867 \sigma_{S} \ln \frac{R_{B}}{r} ; \quad \sigma_{\varphi}=\frac{\sigma_{S}}{\sqrt{3}}\left(\frac{3}{2} \ln \frac{R_{B}}{r}-2\right)=0,578 \sigma_{S}\left(\frac{3}{2} \ln \frac{R_{B}}{r}-1\right) ; \\
\sigma_{z}=\frac{\sigma_{S}}{\sqrt{3}}\left(\frac{3}{2} \ln \frac{R_{B}}{r}-1\right)=0,578 \sigma_{S}\left(\frac{3}{2} \ln \frac{R_{B}}{r}-1\right) .
\end{array}\right\}
$$

Компоненти тензора напружень при пружному чистому циліндричному вигині:

$$
\left.\begin{array}{c}
\sigma_{r}=-\frac{M}{K}\left[3 \ln \frac{r}{\rho}-4+\frac{3}{2} R_{H} R_{B}\left(\frac{1}{r^{2}}+\frac{5}{3 \rho^{2}}\right)\right] ; \sigma_{\varphi}=-\frac{M}{K}\left[3 \ln \frac{r}{\rho}+\frac{5}{2} R_{H} R_{B}\left(\frac{1}{r^{2}}-\frac{1}{\rho^{2}}\right)\right] ; \\
\sigma_{z}=-\frac{M}{K}\left[3 \ln \frac{r}{\rho}-2+\frac{1}{2} R_{H} R_{B}\left(5 \frac{1}{\rho^{2}}-\frac{1}{r^{2}}\right)\right] .
\end{array}\right\}
$$

Складаючи компоненти напружень для пластичних і пружних деформацій, отримуємо вирази для залишкового напруження. При $R_{H}=r \geq \rho$ маємо:

$$
\left.\begin{array}{l}
\sigma_{r}=\frac{\sqrt{3}}{2} \sigma_{S} \ln \frac{R_{H}}{r}+\frac{M}{K}\left[3 \ln \frac{r}{\rho}-4+\frac{3}{2} R_{H} R_{B}\left(\frac{1}{r^{2}}+\frac{5}{3 \rho^{2}}\right)\right] ; \\
\sigma_{\varphi}=\frac{1}{\sqrt{3}} \sigma_{S}\left(\frac{3}{2} \ln \frac{R_{H}}{r}-2\right)+\frac{M}{K}\left[3 \ln \frac{r}{\rho}+\frac{5}{2} R_{H} R_{B}\left(\frac{1}{r^{2}}-\frac{1}{\rho^{2}}\right)\right] ; \\
\left.\sigma_{z}=\frac{1}{\sqrt{3}} \sigma_{S}\left(\frac{3}{2} \ln \frac{R_{H}}{r}-1\right)+\frac{M}{K}\left[3 \ln \frac{r}{\rho}-2+\frac{1}{2} R_{H} R_{B}\left(5 \frac{1}{\rho^{2}}-\frac{1}{r^{2}}\right)\right] \cdot\right]
\end{array}\right\}
$$

При $R_{H}=r \leq \rho$ :

$$
\left.\begin{array}{l}
\sigma_{r}=\frac{\sqrt{3}}{2} \sigma_{S} \ln \frac{R_{B}}{r}+\frac{M}{K}\left[3 \ln \frac{r}{\rho}-4+\frac{3}{2} R_{H} R_{B}\left(\frac{1}{r^{2}}+\frac{5}{3 \rho^{2}}\right)\right] ; \\
\sigma_{\varphi}=\frac{1}{\sqrt{3}} \sigma_{S}\left(\frac{3}{2} \ln \frac{R_{B}}{r}-2\right)+\frac{M}{K}\left[3 \ln \frac{r}{\rho}+\frac{5}{2} R_{H} R_{B}\left(\frac{1}{r^{2}}-\frac{1}{\rho^{2}}\right)\right] ; \\
\sigma_{z}=\frac{1}{\sqrt{3}} \sigma_{S}\left(\frac{3}{2} \ln \frac{R_{B}}{r}-1\right)+\frac{M}{K}\left[3 \ln \frac{r}{\rho}-2+\frac{1}{2} R_{H} R_{B}\left(5 \frac{1}{\rho^{2}}-\frac{1}{r^{2}}\right)\right]
\end{array}\right\}
$$

Формули (24)-(37) є основою математичної моделі для розрахунку напруженодеформованого стану та залишкових напружень при гнутті профілів. В якості прикладу провели розрахунки для сталей 09Г2 та 08кп для випадку гнуття з наступними характеристиками: $R_{B}=1_{\text {мм }} ; R_{H}=2,3_{\text {мм }} ; \mathrm{S}_{0}=1,4_{\text {мм }} ; b=18_{\text {мм . }}$.

Розрахунки проводили у пакеті Mathcad, результати розрахунків наведені на рис. 2. 


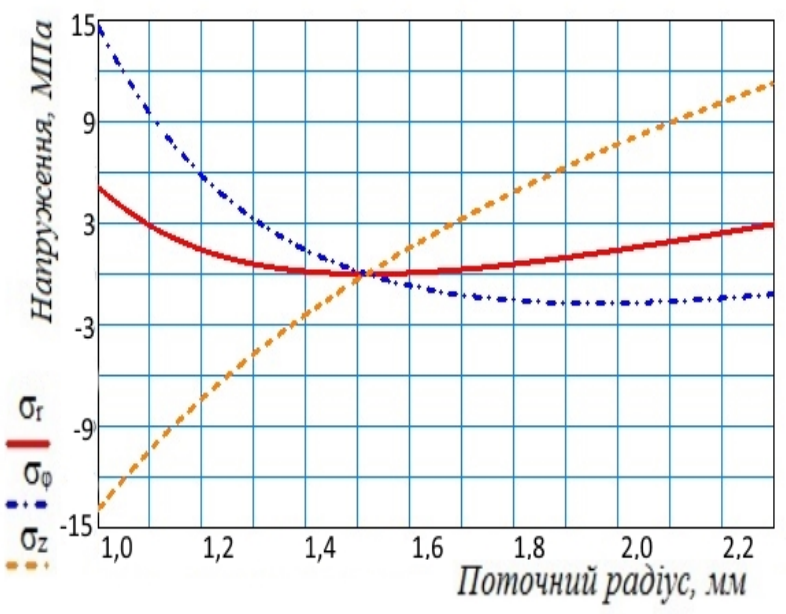

a

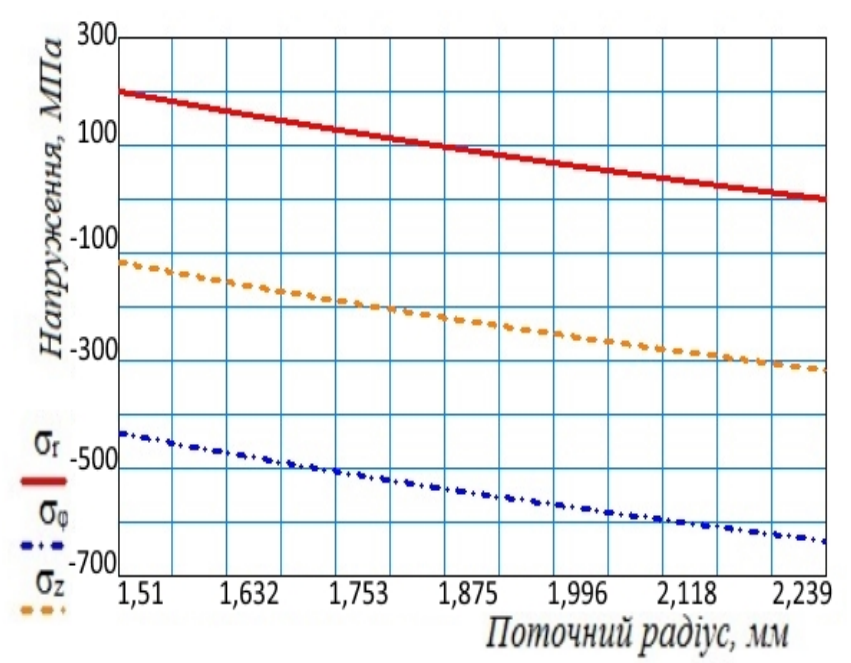

б

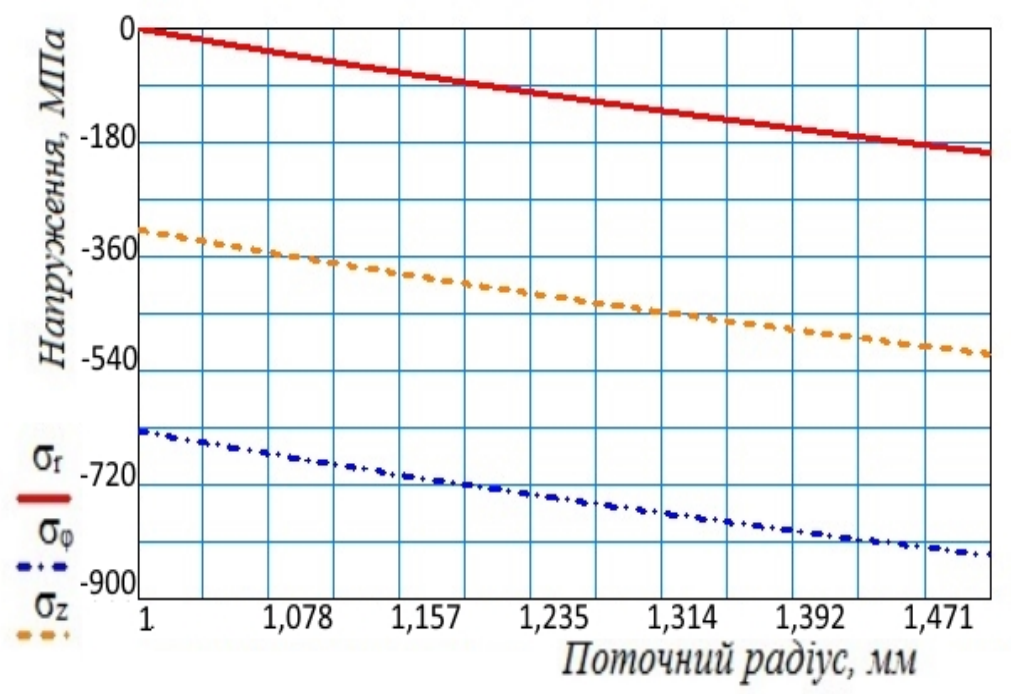

B

Рис. 2. Результати розрахунків напружень по товщині заготовки для сталі 09Г2 по бісектрисі кута згинання:

a - компоненти тензора напружень при пружному чистому циліндричному вигині; б - компоненти залишкового напруження для зовнішнього шару; в - компоненти залишкового напруження для внутрішнього шару

Отримана математична модель дозволяє розраховувати пружинення, деформований стан та залишкові напруження при багатоперехідному гнутті профілів за декілька технологічних переходів із багатьма кутами підгину. Результати дозволяють враховувати кут пружинення при проектуванні валків для гнуття профілів.

Такі розрахунки виконано і для процесів гнуття інших (наприклад 08КП) марок сталі (у роботі не наведені).

\section{ВИСНОВКИ}

Розвинено метод теоретичних досліджень для напружено-деформованого стану у заготовці при гнутті. Показана доцільність використання методів прямих замірів геометричних розмірів заготовок після згинання на різкі кути із врахуванням товщини та ширини заготовки. 
Отриманий аналітичний апарат для розрахунку залишкових напружень, що дозволяє прогнозувати пружинення. Деформації та переміщення у заготовці на стадії проектування технологічної документації. У результаті проведених досліджень процесу гнуття профілів у багатовалкових станах встановлені характеристики полів деформацій та напружень, які залежать від матеріалу заготовок, конфігурації інструмента.

Перспективним напрямком досліджень є розробка аналітичного апарату для процесу багатоперехідного гнуття.

\section{СПИСОК ВИКОРИСТАНОЇ ЛІТЕРАТУРИ}

1. Тришевский И.С., Донец Г.В., Докторов М.Е. и др. Применение гнутых профилей проката: справочник. Москва: Металлургия. 1975. $421 \mathrm{c.}$

2. Naritaa S., Hayakawa K., Kubota Y. Effect of hardening rule for spring back behavior of forging. Procedia Engineering. 2017. 207. pp. 167-172.

3. Banabic D. Sheet metal forming processes, constitutive modeling and numerical simulation. Berlin: Springer-Verlag. 2010, 318 p.

4. Muthler A., Düster A., Volk W., Wagner M., Ranka E. High order thin-walled solid finite elements applied to elastic spring-back computations. Computer Methods in Applied Mechanics and Engineering. 2006. Vol. 195, pp. 41-43.

5. Gupta S., Ramana-Reddy D. Design and analysis of aircraft sheet metal for spring back effect. Materials Today: Proceedings. 2017. Vol. 4, pp. 8287-8295.

6. Fu Z., Mo. J., Zhang W. Study on multiple-step incremental air-bending forming of sheet metal with springback model and FEM simulation. The International Journal of Advanced Manufacturing Technology. 2009. Vol. 45, pp. $448-458$.

7. Малинин Н.Н. Прикладная теория пластичности и ползучести. Москва: Машиностроение. 1975. 399 с.

8. Tekaslan Ö., Gerger N., Şeker U. Determination of spring-back of stainless steel sheet metal in "V" bending dies. Materials and Design. 2008, Vol. 29. pp. 1043-1050.

9. Xia Z.C. Constitutive modeling of advanced high-strength steels for spring back simulation. Computational Mechanics. Springer, Berlin, Heidelberg. 2007, 299 p.

10. Yu T.X. Influence of axial force on elastic-plastic bending and springback of a beam. Journal of Mechanical Working Technology. 1982, 6, pp. 5-21.

11. Thipprakmas S. Finite Element Analysis on V-Die Bending Process. Finite Element Analysis. Ed. David Moratal. Sciyo. 2010, pp. 407-428.

12. Nandanwar P.S., Bajaj P.S., Patil P.D. Analysis of spring back defect in right angle bending process in sheet metal forming. International Journal of Science, Spirituality, Business and Technology. 2014, 3 (1), pp. 18-22.

13. Viorel P., Saadatou A.S., Nedelcu D., Octavian M. Experimental and numerical investigations of sheet metal circular bending. Indian Journal of Engineering and Materials Sciences. 2015, 22, pp. 487-496.

14. Hama T., Banu M. Effects of finite element type on springback simulation of a high strength steel sheet. The Annals of "Dunărea de Jos" University of Galati, Fascicle V, Technologies in Machine Building. 2009 , pp. 75-80.

15. Kukhar V., Balalayeva E., Nesterov O. Calculation method and simulation of work ofthe ring elastic compensator for sheet-forming. MATEC Web of Conferences. 2017, 129, p. 01041.

16. Кухар В.В., Аніщенко О.С., Нагнібеда М.М. Методика розрахунку напружено-деформованого стану листової заготовки при гнутті з врахуванням зміцнення матеріалу. Вісник НТУ «ХПІ»: Серія: Інноваційні технологї̈ та обладнання ОМД у машинобудуванні та металургії. 2017.37 (1259). С. 36-41.

17. Алексеев Ю.Н. Введение в теорию обработки металлов давлением, прокаткой и резанием. Харьков: Изд-во ХГУ. 1969. 107 с.

18. Ильюшин А.А. Механика сплошной среды. Москва: Изд-во МГУ. 1990. 285 с.

19. Алексеев Ю.Н. Вопросы пластического течения металлов. Харьков: Изд-во ХГУ. 1958. 188 с.

20. Шемшурова Н.Г., Ионова О.В., Локотушина Н.М., Седова Е.М. Методика определения показателя прочности холодногнутого профиля. Моделирование и развитие прощессов обработки металлов давлением: Межрегион. сб. науч. тр. Магнитогорск: ГОУ ВПО «МГТУ». 2007. С. 215-219.0

21. Кухарь В.В., Нагнибеда Н.Н. Испытание армирующих профилей и определение их прочностных и геометрических характеристик. Проблемы трибологии. Problems of tribology. Хмельницький: ХНУ. 2016. 1(79). С. $30-35$. 


\section{REFERENCES}

1. Trishevsky I.S., Donets G.V., Doctors M.E. et al. The use of bent profiles of hire: Handbook. Moscow: Metallurgy. 1975, 421 p. (in Russian).

2. Naritaa S., Hayakawa K., Kubota Y. Effect of hardening rule for spring back behavior of forging. Procedia Engineering. 2017, 207, pp. 167-172.

3. Banabic D. Sheet metal forming processes, constitutive modeling and numerical simulation. Berlin: Springer-Verlag. 2010, 318 p.

4. Muthler A., Düster A., Volk W., Wagner M., Ranka E. High order thin-walled solid finite elements applied to elastic spring-back computations. Computer Methods in Applied Mechanics and Engineering. 2006, 195, pp. 41-43.

5. Gupta S., Ramana-Reddy D. Design and analysis of aircraft sheet metal for spring back effect. Materials Today: Proceedings. 2017, 4, pp. 8287-8295.

6. Fu Z., Mo J., Zhang W. Study on multiple-step incremental air-bending forming of sheet metal with springback model and FEM simulation. The International Journal of Advanced Manufacturing Technology. 2009, 45, pp. 448-458.

7. Malinin N. N. Applied theory of plasticity and creep. Moscow: Mechanical Engineering. 1975, 399 p. (in Russian).

8. Tekaslan O., Gerger N., Şeker U. Determination of spring-back of stainless steel sheet metal in "V" bending dies. Materials and Design. 2008, 29, pp. 1043-1050.

9. Xia Z.C. Constitutive modeling of advanced high-strength steels for spring back simulation. Computational Mechanics. Springer, Berlin, Heidelberg. 2007, 299 p.

10. Yu T.X. Influence of axial force on elastic-plastic bending and springback of a beam. Journal of Mechanical Working Technology. 1982, 6, pp. 5-21.

11. Thipprakmas S. Finite Element Analysis on V-Die Bending Process. Finite Element Analysis. Ed. David Moratal. Sciyo. 2010, pp. 407-428.

12. Nandanwar P.S., Bajaj P.S., Patil P.D. Analysis of spring back defect in right angle bending process in sheet metal forming. International Journal of Science, Spirituality, Business and Technology. 2014, 3 (1), pp. 18-22.

13. Viorel P., Saadatou A.S., Nedelcu D., Octavian M. Experimental and numerical investigations of sheet metal circular bending. Indian Journal of Engineering and Materials Sciences. 2015, 22, pp. 487-496.

14. Hama T., Banu M. Effects of finite element type on springback simulation of a high strength steel sheet. The Annals of "Dunărea de Jos" University of Galati, Fascicle V, Technologies in Machine Building. 2009, pp. 75-80.

15. Kukhar V., Balalayeva E., Nesterov O. Calculation method and simulation of work ofthe ring elastic compensator for sheet-forming. MATEC Web of Conferences. 2017, 129, p. 01041.

16. Kukhar V.V., Anishchenko O.S., Nagnibeda M.M. Method of calculation of stress-strain state of sheet billet in bending taking into account material strengthening. Bulletin of NTU "KhPI". 2017, 37 (1259), pp. 36-41. (in Ukrainian).

17. Alekseev Yu.N. Introduction to the theory of metal processing by pressure, rolling and cutting. Kharkov: Publishing House of KhSU. 1969, 107 p. (in Russian). (in Russian).

18. Ilyushin A.A. Mechanics of a continuous medium. Moscow: Publishing House of MSU. 1990, 285 p. (in Russian).

19. Alekseev Yu.N. Issues of the plastic flow of metals. Kharkov: Publishing House of KhSU. 1958,188 p.

20. Shemshurova N.G., Ionova O.V., Lokotushina N.M., Sedova E.M. Method for determining the strength index of a cold-formed profile. Modeling and development of metal forming processes: collection of scientific papers. Magnitogorsk: MSTU. 2007, pp. 215-219. (in Russian).

21. Kukhar V.V., Nagnibeda N.N. Testing of reinforcing profiles and determination of their strength and geometric characteristics. Problems of tribology. Khmelnitsky: KhNU. 2016, 1 (79), pp. 30-35. (in Russian).

Кухар В. В. $\quad$ - д-р техн. наук, проф., зав. каф. ОМТ ПДТУ;

Нагнібеда М. М. - аспірант ПДТУ.

ПДТУ - Приазовський державний технічний університет, м. Маріуполь.

E-mail: fox7941@gmail.com 